13

\title{
Формирование силицидов железа под графеном, выращенным на поверхности карбида кремния
}

\author{
(ㄱ Г.С. Гребенюк ${ }^{1}$, И.А. Елисеев ${ }^{1}$, С.П. Лебедев ${ }^{1,2}$, Е.Ю. Лобанова ${ }^{2}$, Д.А. Смирнов ${ }^{3}$, \\ В.Ю. Давыдов ${ }^{1}$, А.А. Лебедев ${ }^{1}$, И.И. Пронин ${ }^{1, \uparrow}$ \\ ${ }^{1}$ Физико-технический институт им. А.Ф. Иофрфе РАН, \\ Санкт-Петербург, Россия \\ ${ }^{2}$ Университет ИТМО, \\ Санкт-Петербург, Россия \\ ${ }^{3}$ Institute of Solid State Physics, Dresden University of Technology, \\ Dresden, Germany \\ ฯ E-mail: Igor.Pronin@mail.ioffe.ru
}

Поступила в Редакцию 13 апреля 2020 г.

В окончательной редакции 13 апреля 2020 г.

Принята к публикации 21 апреля 2020 г.

\begin{abstract}
Исследован процесс формирования тонких пленок силицидов железа под графеном, выращенным на поверхности карбида кремния, путем последовательного интеркалирования графена атомами железа и кремния. Эксперименты проводились in situ в условиях сверхвысокого вакуума. Элементный состав и химическое состояние поверхности образцов, а также их атомная структура контролировались с помощью фотоэлектронной спектроскопии высокого энергетического разрешения с использованием синхротронного излучения и дифракции медленных электронов. Толщина нанесенных слоев железа и кремния варьировалась в диапазоне 0.1-2nm, а температура отжига образцов изменялась от комнатной до $600^{\circ} \mathrm{C}$. Показано, что интеркалирование системы графен $/ \mathrm{Fe} / \mathrm{SiC}$ кремнием приводит к образованию слоя твердого раствора $\mathrm{Fe}-\mathrm{Si}$, покрытого поверхностным силицидом $\mathrm{Fe}_{3} \mathrm{Si}$. Полученные пленки надежно защищены графеном от воздействия окружающей среды, что открывает возможности для их практического применения.
\end{abstract}

Ключевые слова: графен на карбиде кремния, железо, интеркалирование, силициды, фотоэлектронная спектроскопия.

DOI: $10.21883 / F T T .2020 .10 .49929 .091$

\section{1. Введение}

В последние годы граница раздела графена с ферромагнитными материалами привлекает повышенный интерес исследователей благодаря необычным физическим свойствам этих систем и их возможного применения в спиновых фильтрах и других устройствах спинтроники [1-3]. К настоящему времени большинство работ связано с выращиванием графена непосредственно на поверхности металлов с помощью химического осаждения из газовой фазы. Однако одним из наиболее перспективных методов роста высококачественного эпитаксиального графена является сублимация кремния из монокристаллической диэлектрической подложки карбида кремния [4]. Большим преимуществом этой технологии является отсутствие необходимости переносить выращенную пленку графена на диэлектрическую подложку, как это имеет место в случае роста графена на металлах. Кроме того, эта технология позволяет выращивать графен на поверхности коммерческих подложек $\mathrm{SiC}$ большого диаметра, что позволяет интегрировать его в стандартную линейку изготовления полупроводниковых приборов.

Контакт графена с ферромагнетиком в системе графен/SiC может быть создан с помощью интеркалиро- вания, то есть внедрения атомов магнитных металлов под слой графена. Этот подход недавно был применен для формирования интерфейсов графен $/ \mathrm{Fe} / \mathrm{SiC}$ и графен/Co/SiC [3,5-9]. Помимо металлов группы железа перспективными материалами для модификации электронной и спиновой структуры графена являются и силициды этих металлов. Преимуществом силицидов является большое многообразие их физических свойств, позволяющее создавать различные электронные устройства. Например, ферромагнитный силицид $\mathrm{Fe}_{3} \mathrm{Si}$ благодаря своим полуметаллическим свойствам является перспективным материалом для инжекции спинполяризованных электронов в графен. Кроме того, графен, контактирующий с силицидами железа и кобальта, находится в квазисвободном состоянии [10,11]. Однако, в литературе отсутствуют данные по формированию силицидов железа в системе графен/SiC. Поэтому целью настоящей работы и стало исследование процессов формирования ультратонких пленок силицидов железа под графеном, выращенным на карбиде кремния.

\section{2. Техника эксперимента}

Графен формировался на высокоомных пластинах $\mathrm{SiC}$ политипа $6 \mathrm{H}$ размером $5 \times 5 \mathrm{~mm}$ методом термического 


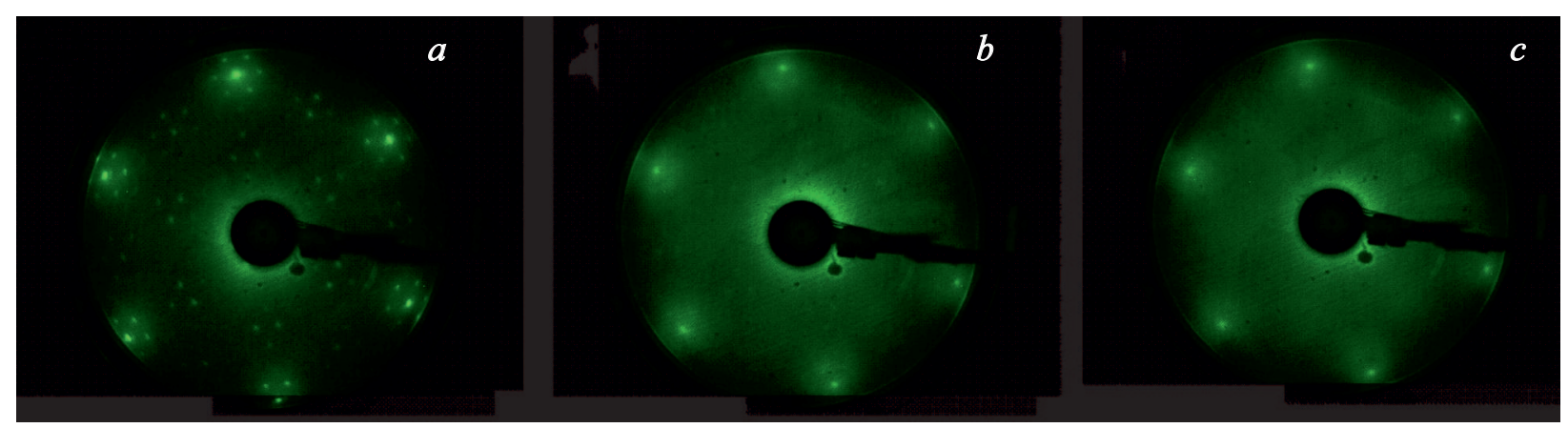

Рис. 1. Картины ДМЭ, полученные при энергии $76 \mathrm{eV}$ для образца $\mathrm{Gr} / \mathrm{SiC}$ с чистой поверхностью $(a)$ и после интеркалирования железом $(b)$ и кремнием $(c)$.

разложения карбида кремния в среде инертного газа (аргона) [12]. Данная технология позволяет точнее контролировать процесс сублимации компонентов карбида кремния по сравнению с разложением $\mathrm{SiC}$ в вакууме, что позволяет управлять ростом пленки графена. Метод термического разложения состоит в том, что при высокой температуре $\left(>1100^{\circ} \mathrm{C}\right)$ в приповерхностном слое $\mathrm{SiC}$ происходят процессы диффузии и сублимации атомов кремния, приводящие к повышению концентрации углерода на поверхности с образованием графена. Полученные образцы представляли собой монослойный графен высокого качества с небольшой долей $(\sim 10 \%)$ включений двухслойных островков с субмикронными размерами. Их структурные, химические и электронные характеристики соответствовали конечному этапу оптимизации технологических параметров в работе [12].

Основные эксперименты по формированию силицидов железа под графеном проводились на оборудовании Российско-Германского канала вывода синхротронного излучения накопительного кольца BESSY II (Берлин). Они были выполнены in situ в условиях сверхвысокого вакуума. На первой стадии эксперимента образцы подвергались очистке путем длительного прогрева при температуре $500^{\circ} \mathrm{C}$. В работе была использована оригинальная методика, которая включает в себя два этапа: интеркалирование графена на $\mathrm{SiC}$ атомами железа и интеркалирование системы графен/ $\mathrm{Fe} / \mathrm{SiC}$ атомами кремния. Интеркалирование графена железом и кремнием проводилось путем нанесения на поверхность образцов атомов соответствующих материалов и последующего отжига пленок при различных температурах в течение $10 \mathrm{~min}$. Толщина напыляемых пленок контролировалась с помощью кварцевых микровесов и варьировалась в диапазоне $0.1-2 \mathrm{~nm}$.

Контроль элементного и химического состава поверхности образцов, а также их атомного строения проводился методами фотоэлектронной спектроскопии (ФЭС) высокого энергетического разрешения с использованием синхротронного излучения и дифракции медленных электронов (ДМЭ). Энергия фотонов варьировалась в интервале 80-600 eV. Регистрация спектров фотоэлек- тронов проводилась с помощью сверхвысоковакуумного спектрометра PHOIBOS 150 с 200-миллиметровым полусферическим энергоанализатором. Полное энергетическое разрешение прибора (включая разрешение монохроматора) составляло $100 \mathrm{meV}$. Исследования структурных характеристик образцов проводилось методом комбинационного рассеяния света (КРС). Данные, полученные методом КРС и характеризующие качество исходных образцов, приведены в работе [8].

\section{3. Результаты и их обсуждение}

Данные, полученные после очистки поверхности графена в вакууме, представлены на рисунках 1-2. На рис. 1, $a$ показана типичная картина ДМЭ при энергии $76 \mathrm{eV}$. В ней хорошо видна структура $(6 \sqrt{3} \times 6 \sqrt{3}) \mathrm{R} 30^{\circ}$, характерная для графена, выращенного на карбиде кремния [13]. Она возникает вследствие несовпадения периодов решеток графена и поверхности $\mathrm{SiC}(0001)$. Четкость рефлексов свидетельствует о строгой согласованности решеток графена и подложки. Типичный фотоэлектронный спектр остовных C $1 s$ электронов, измеренный при энергии фотонов $470 \mathrm{eV}$, показан на рис. 2, a. Он соответствует данным, полученным в работах $[8,12,14]$, и свидетельствует о высоком качестве исходного однослойного графена на поверхности $\mathrm{SiC}$. На этом же рисунке показаны результаты разложения измеренного спектра на составляющие. Линия С $1 s$ состоит из четырех компонент: мода $\mathrm{SiC}$ соответствует атомам углерода из подложки $\mathrm{SiC}$, мода $\mathrm{G}$ - атомам графена, а моды $\mathrm{S}_{1}$ и $\mathrm{S}_{2}$ связаны с наличием буферного слоя между графеном и подложкой. Причем компонента $\mathrm{S}_{1}$ соответствует атомам углерода, которые связаны со слоем атомов кремния из $\mathrm{SiC}, \mathrm{S}_{2}$ - атомам углерода, несвязанным с этим слоем. При этом интенсивность моды $\mathrm{S}_{2}$ в два раза больше интенсивности моды $\mathrm{S}_{1}$ [15].

Процесс интеркалирования графена, выращенного на карбиде кремния, железом рассмотрен в нашей более ранней работе [8]. В ней показано, что оптимальные условия интеркалирования реализуются в диапазоне 400-500 ${ }^{\circ}$. Также продемонстрирована возможность 
защиты графеном от воздействия кислорода интеркалированных под него пленок железа толщиной до $2 \mathrm{~nm}$.

Более подробно рассмотрим вторую стадию синтеза силицидов железа покрытых графеном. Из данных, представленных на рис. 2, хорошо видно, что после
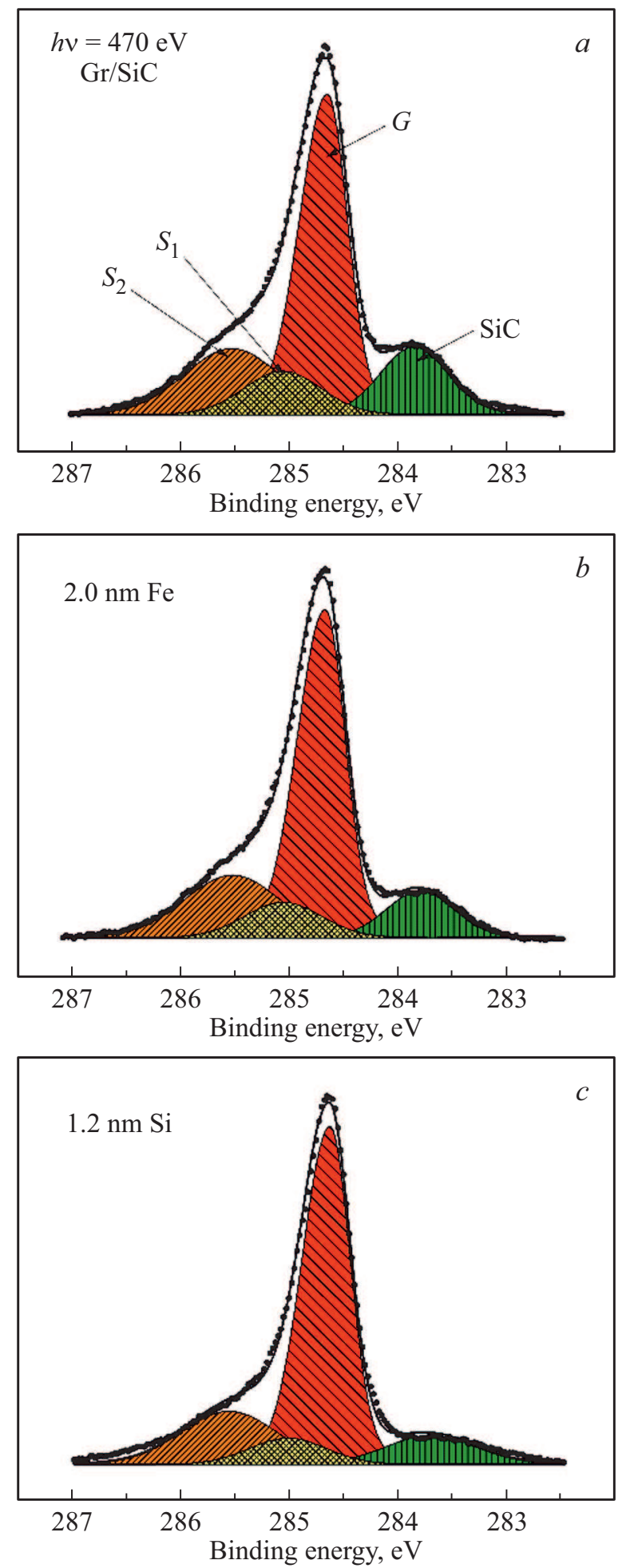

Рис. 2. Спектры C $1 s$, измеренные на разных стадиях процесса интеркалирования графена железом и кремнием при энергии фотонов $470 \mathrm{eV}$, и результаты их разложения на составляющие.
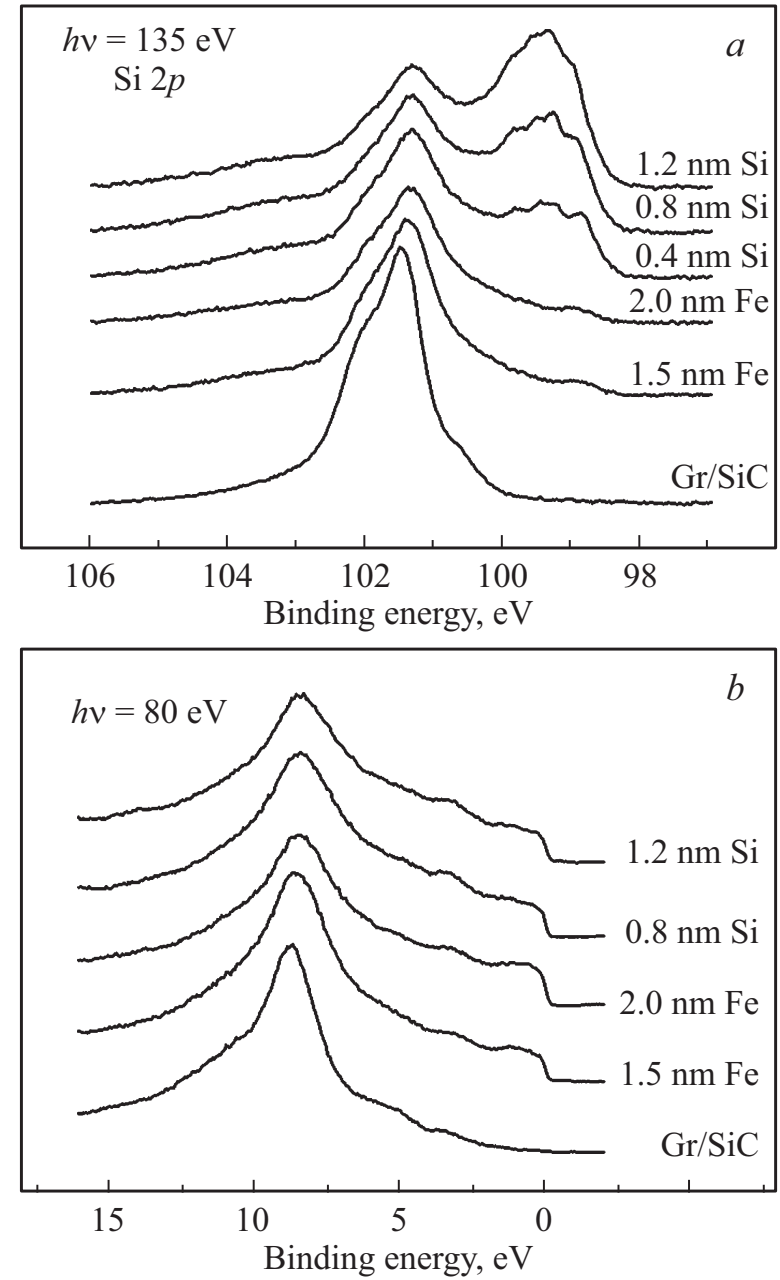

Рис. 3. Спектры Si $2 p(a)$ и валентных электронов $(b)$, измеренные в ходе интеркалирования графена железом и кремнием при энергиях фотонов 135 и $80 \mathrm{eV}$ соответственно.

нанесения кремния и отжига образца, моды подложки и буферного слоя убывают, а мода, соответствующая графену, остается практически неизменной, что свидетельствует о миграции атомов с поверхности образца под пленку графена. Таким образом, происходит интеркалирование графена кремнием. Этот вывод подтверждается также данными рис. 1, $c$, на котором показана картина ДМЭ, наблюдавшаяся после интеркалирования графена кремнием. В ней рефлексы, соответствующие карбиду кремния, почти полностью исчезают, а остаются лишь рефлексы, характерные для графена.

Типичные спектры остовных $\mathrm{Si} 2 p$-электронов кремния, измеренные до и после интеркалирования графена, показаны на рис. 3,a. Видно, что интеркалирование графена железом оказывает слабое влияние на форму линии спектра, определяемую подложкой карбида кремния, и основной эффект состоит в уменьшении ее интенсивности. В свою очередь интеркалирование графена кремнием не только усиливает эту тенденцию, но и приводит к появлению новых особенностей в $\mathrm{Si} 2 p$-спектре, 
возникающих в области энергий связи $98-100 \mathrm{eV}$. Этот диапазон энергий характерен для силицидов железа, поэтому появление и последующее усиление отмеченных особенностей свидетельствует о протекании процесса силицидообразования в данной системе.

Данные, иллюстрирующие динамику изменения спектров валентных электронов в ходе интеркалирования, показаны на рис. $3, b$. Основной особенностью этих спектров является максимум при энергии $9.7 \mathrm{eV}$, который соответствует $\pi$-состоянию графена [16]. Интеркалирование графена железом и кремнием слабо влияет на данный пик, что говорит о сохранении высокого качества графеновой пленки. В то же время оно приводит к резкому повышению плотности электронных состояний вблизи уровня Ферми, обусловленных валентными электронами железа и кремния.

Проанализируем теперь более подробно особенности спектров остовных Si $2 p$-электронов, появляющиеся после интеркалирования образцов кремнием. На рис. 4 показаны характерные разностные спектры, полученные из исходных кривых путем вычитания фона неупругорассеянных электронов, а также сигнала от подложки карбида кремния. Для наглядности сопоставления данных спектры нормированы на максимальное значение интенсивности. Левый спектр был измерен после напыления на образец пленки кремния толщиной $0.4 \mathrm{~nm}$ и последующего ее отжига при температуре $400^{\circ} \mathrm{C}$. В нем хорошо видны максимумы, которые обусловлены формированием под графеном силицидов железа при химическом взаимодействии атомов $\mathrm{Fe}$ и $\mathrm{Si}$. Как видно из рисунка спектр хорошо аппроксимируется двумя спин-орбитальными дублетами (B и $S)$. Энергии связи компонент $\mathrm{Si} 2 p_{3 / 2}$ этих дублетов равны соответственно 99.3 и $98.9 \mathrm{eV}$. Эти значения хорошо согласуются с энергиями связи силицидов железа, формирующихся под графеном в системе $\mathrm{Gr} / \mathrm{FeSi} / \mathrm{Ni}$ [9]. Мода с меньшей энергией связи $(S)$ усиливается с уменьшением энергии фотонов, что позволяет связать ее с поверхностной фазой силицида железа $\mathrm{Fe}_{3} \mathrm{Si}$ [9]. Мода $B$, характеризуемая более высокой энергией, отвечает твердому раствору $\mathrm{Fe}-\mathrm{Si}$ - кремния в железе и связана с атомами кремния, которые проникли глубже в слой интеркалированного $\mathrm{Fe}$. Увеличение дозы интеркалирующего кремния приводит к обогащению этого слоя атомами Si. В результате толщина пленки твердого раствора кремния в железе увеличивается. Спектры, полученные после интеркалирования графена $\mathrm{Si}$ толщиной 0.8 и $1.2 \mathrm{~nm}$, показаны на рис. $4, b$ и $c$ соответственно. Эти спектры состоят из тех же мод, что и спектр на рис. $4, a$, однако, с увеличением количества кремния повышается интенсивность компоненты $B$, которая соответствует твердому раствору $\mathrm{Fe}-\mathrm{Si}$.

Анализ отношения интенсивностей линий кремния и железа, полученных для различных компонент $\mathrm{Si}$ $2 p$-спектра, позволяет оценить элементный состав образующихся силицидов. С его помощью было подтверждено, что стехиометрия верхнего слоя, расположенного под графеном, соответствует силициду $\mathrm{Fe}_{3} \mathrm{Si}$, а концентрация кремния в твердом растворе $\mathrm{Fe}-\mathrm{Si}$ составляет примерно 15 at.\%, что соответствует составу $\mathrm{Fe}_{x} \mathrm{Si}$, где $x=6$.
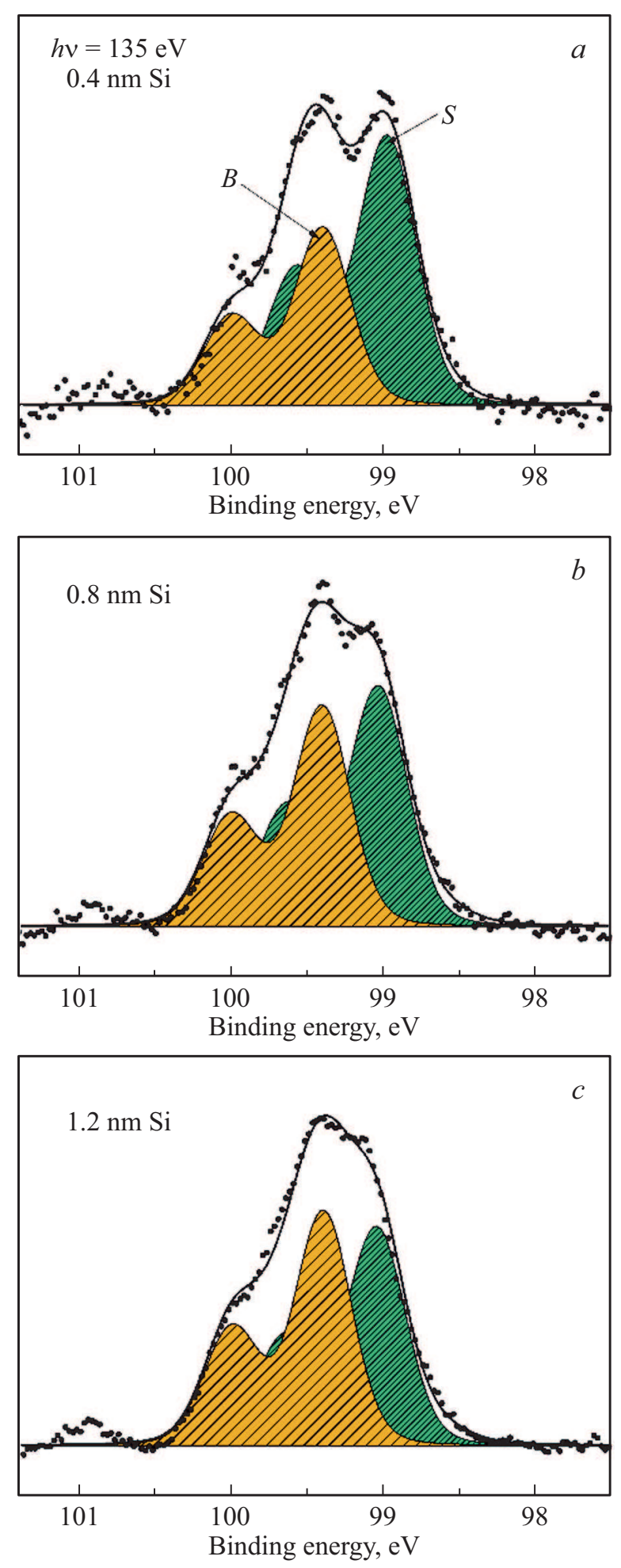

Рис. 4. Спектры $\mathrm{Si} 2 p$, измеренные на разных стадиях процесса интеркалирования графена железом и кремнием при энергии фотонов $135 \mathrm{eV}$, и результаты их разложения на составляющие. 


\section{4. Заключение}

В работе исследован процесс формирования силицидов железа под графеном, выращенным на поверхности карбида кремния. Эксперименты проведены in situ в условиях сверхвысокого вакуума методами фотоэлектронной спектроскопии высокого энергетического разрешения с использованием синхротронного излучения и дифракции медленных электронов. Апробирован новый способ формирования силицидов железа под графеном на $\mathrm{SiC}$, заключающийся в последовательном интеркалировании графена железом и кремнием. Показано, что использование такой процедуры приводит к образованию под графеном поверхностного силицида $\mathrm{Fe}_{3} \mathrm{Si}$ и твердого раствора $\mathrm{Fe}-\mathrm{Si}$ с содержанием кремния около 15\%. Изменяя количество интеркалируемых материалов и температуру образца, можно менять толщину и состав формируемых пленок. Синтезированный силицид при этом защищен графеном от воздействия кислорода окружающей среды.

\section{Финансирование работы}

Авторы благодарят Российско-Германскую лабораторию на BESSY II и Helmholtz-Zentrum Berlin за возможность использования синхротронного излучения.

\section{Список литературы}

[1] Yu. Dedkov, E. Voloshina. J. Phys.: Condens. Mater. 27, 303002 (2015).

[2] A.D. Vu, J. Coraux, G. Chen, A.T. N'Diaye, A.K. Schmid, N. Rougemaille. Sci. Rep. 6, 24783 (2016).

[3] R. Hoenig, P. Roese, K. Shamout, T. Ohkochi, U. Berges, C. Westphal. Nanotechnology 30, 025702 (2019).

[4] K.V. Emtsev, A. Bostwick, K. Horn, J. Jobst, G.L. Kellogg, L. Ley, J.L. Mc Chesney, T. Ohta, S.A. Reshanov, J. Rohrl, E. Rotenberg, A.K. Schmid, D. Waldmann, H.B. Weber, T. Seyller. Nature Mater. 8, 203 (2009).

[5] S.J. Sung, J.W. Yang, P.R. Lee, J.G. Kim, M.T. Ryu, H.M. Park, G. Lee, C.C. Hwang, Kwang. S. Kim, J.S. Kim, J.W. Chung. Nanoscale 6, 382 (2014).

[6] Y. Zhang, H. Zhang, Y. Cai, J. Song, P. He. Nanotechnology 28, 075701 (2017)

[7] K. Shen, H. Sun, J. Hu, J. Hu, Z. Liang, H. Li, Z. Zhu, Y. Huang, L. Kong, Y. Wang, Z. Jiang, H. Huang, J.W. Wells, F. Song. J. Phys. Chem. C 122, 21484 (2018).

[8] М.В. Гомоюнова, Г.С. Гребенюк, В.Ю. Давыдов, И.А. Ермаков, И.А. Елисеев, А.А. Лебедев, С.П. Лебедев, Е.Ю. Лобанова, А.Н. Смирнов, Д.А. Смирнов, И.И. Пронин. ФТТ 60, 1423 (2018).

[9] Г.С. Гребенюк, Е.Ю. Лобанова, Д.А. Смирнов, И.А. Елисеев, А.В. Зубов, С.П. Лебедев, В.Ю. Давыдов, А.А. Лебедев, И.И. Пронин. ФТТ 61, 1374 (2019).

[10] G.S. Grebenyuk, O.Yu. Vilkov, A.G. Rybkin, M.V. Gomoyunova, B.V. Senkovskiy, D.Yu. Usachov, D.V. Vyalikh, S.L. Molodtsov, I.I. Pronin. Appl. Surf. Sci. 392, 715 (2017).
[11] G.S. Grebenyuk, S.M. Dunaevsky, E.Yu. Lobanova, D.A. Smirnov, I.I. Pronin. Appl. Surf. Sci. 470, 840 (2019).

[12] В.Ю. Давыдов, Д.Ю. Усачёв, С.П. Лебедев, А.Н. Смирнов, В.С. Левицкий, И.А. Елисеев, П.А. Алексеев, М.С. Дунаевский, О.Ю. Вилков, А.Г. Рыбкин, А.А. Лебедев. ФТП 51, 1116 (2017).

[13] C. Riedl, C. Coletti, U. Starke. J. Phys. D 43, 374009 (2010).

[14] S.J. Sung, J.W. Yang, P.R. Lee, J.G. Kim, M.T. Ryu, H.M. Park, G. Lee, C.C. Hwang, K.S. Kim, J.S. Kim, J.W. Chung. Nanoscale 6, 382 (2014)

[15] K.V. Emtsev, F. Speck, T. Seyller, L. Ley. Phys. Rev. B 77, 155303 (2009).

[16] A. Generalov, Yu. Dedkov. Carbon 50, 183 (2011).

Редактор К.В. Емцев 